\title{
FÁCIES, AMBIENTES E CARVÕES NA FORMAÇÃO RIO BONITO, NO SUL DO ESTADO DO PARANÁ: UMA ANÁLISEE ESTRATIGRÁFICA
}

\author{
JOSÉ HENRIQUE POPP*
}

\begin{abstract}
The results obtained through stratigraphic analysis on a regional scale, in the Rio Bonito Formation (Lower Permian of the Paraná Basin), are presented herein. The survey was performed over an area of about $3000 \mathrm{~km}^{2}$, in the southern region of the State of Paraná.

The main purpose of the research was to analyse the faciologic and depositional parameters of the coal bearing deposit and the possibility of its economic exploitation.

About 90 well logs and several field sections were studied.

The interpretation of the sedimentary environment was made through the formats (curve shapes) of gamma rays and resistivity logs related to physical properties of the facies, supplemented by lithologic control from outcrop description and samples from strategically located wells.

The lower member of Rio Bonito Formation (Triunfo Member) was originated in a deltaic province prograding over prodeltaic siltstones of an epicontinental shallow sea.

The upper part of this member is of a retrogradacional nature, being covered by transgressive marine deposits of the Paraguaçu Member.

In the interdistributary bay of the deltaic plains of the Triunfo Member several peat swamps and marches were formed.

Owing to high clastic influx and low subsidence rate, the peat accumulation was thin, being preserved as coal beds thinner than $50 \mathrm{~cm}$ with a high ash content.

These elements justify the exclusion of about all the coal bearing layers of the area, as far as its economic exploitation is concerned.
\end{abstract}

INTRODUÇÃo Este trabalho consiste em uma análise dos parâmetros estratigráficos e litofaciológicos, objetivando a compreensão dos padrões paleodeposicionais e suas relações com a gênese do carvão na Formação Rio Bonito, Permiano da Bacia do Paraná.

A identificação e a inter-relação das fácies foram feitas a partir da interpretação do significado dos formatos das cur. vas de raios gama e resistividade, associadas aos estudos de testemunhos de sondagens e trabalhos de campo.

Entre cerca de 85 poços perfurados na área pelo DNPM, Nuclan e Petrobrás, foram utilizados 40 e consultados outros tantos para informações suplementares.
Como consequência, elaborou-se uma divisão faciológica operacional, estabelecendo-se os modelos de sedimentação dominante na época e suas relaçð̋es com a formação e acumulação do carvão.

Tratando-se de uma área ainda não avaliada quanto às reais possibilidades carboniferas, os resultados dos estudos mostraram que em sua maior parte diversos fatores foram impróprios para a formação e acumulação do carvão, indicando algumas que poderão ser objeto de estudos mais pormenorizados.

A área estudada situa-se na faixa aflorante das formaçðes Rio Bonito, Palermo e Irati, até uma profundidade média

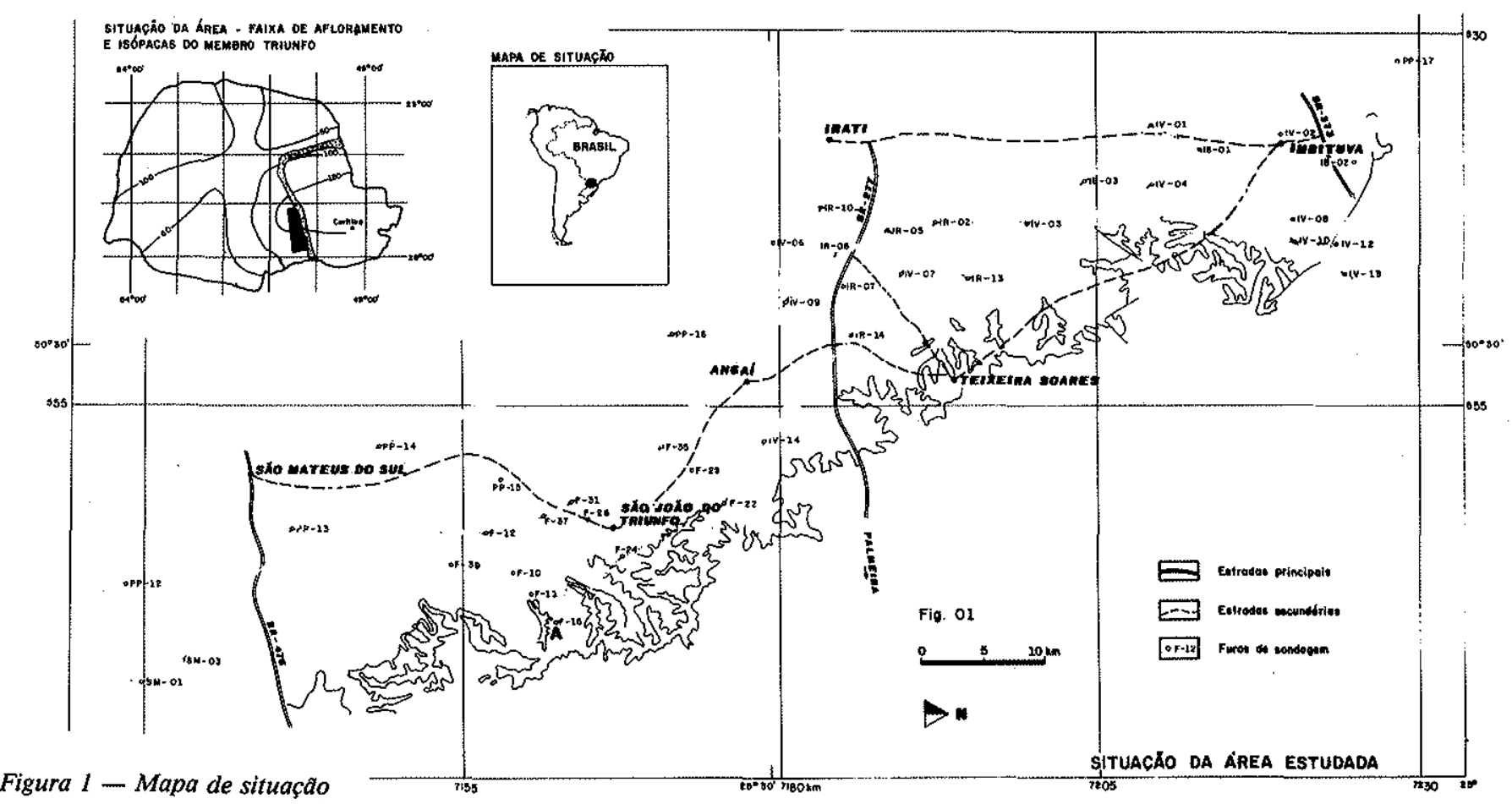

* Departamento de Geologia, Universidade Federal do Paraná, (UFPr), Paraná, Brasil 
dos $200 \mathrm{~m}$, da região de São Mateus do Sul a Inbituva, numa extensão de aproximadamente $120 \mathrm{~km}$, perfazendo cerca de $3000 \mathrm{~km}^{2}$ (Fig. 1).

TRABALHOS EXECUTADOS E METODOLOGIA Digitalização de dados litológicos As informações litológicas extraídas da descrição dos perfís dos poços utilizados na construção dos mapas foram digitalizadas, de forma que os dados quantitativos referentes a cada poço fossem determinados, proporcional e percentualmente, em seçð̃es de $5 \mathrm{em}$ $5 \mathrm{~m}$.

Este procedimento objetivou homogeneizar as informações.

Correlação de perfis A correlação foi feita a partir dos perfis em escala 1:200. Em seguida, procurou-se caracterizar os formatos dos perfis de raios gama, definir marcos e associar a resposta de seqüências litológicas similares e comuns à maioria dos póços.

Subdivisão da seqüência A seqüência estudada foi dividida verticalmente, do topo para a base, em intervalos limitados por horizontes denominados $A, A, B, C, D$ e $E$.

Estes intervalos são a expressão dos padrões de variação dos parâmetros físicos dos perfis resultantes das diversas associações litológicas que compõem os diferentes pacotes na sequêência (Fig. 2).

Os intervalos compreendidos entre esses horizontes foram utilizados para a confecção dos mapas anexos.

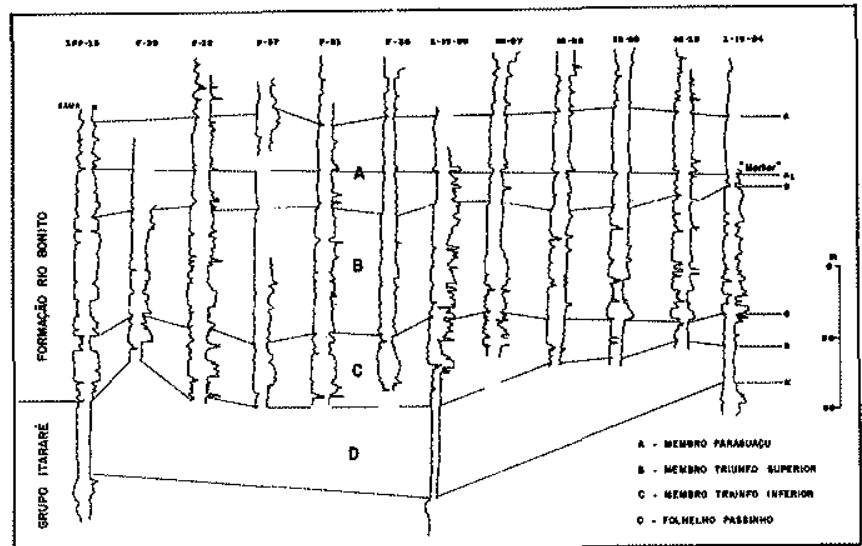

Figura 2 - Litoestratigrafia, divisao em intervalos e exemplo de correlação entre alguns poços utilizados

Análise de fácies Os.estudos das fácies foi feito de acordo com os formatos dos perfis de raios gama e resistividade, embora houvesse o inconveniente de enriquecimentos epigenéticos em minerais radiativos, tanto nos arenitos como nos pelitos, comuns nesta área.

Não obstante esse inconveniente, os estudos mostraram a utilidade dos perfis raios gama na interpretação de fácies genéticas, conforme já havia sido verificado por Selley (1976), Rehbein (1978) e Perrodon (1980).

PERFIS DE RESISTIVIDADE Os registros de resistência $R$ fornecem bom detalhamento na identificação de finas camadas existentes numa seqüência litológica, notadamente nas sedimentares, em que arenitos, siltitos e folhelhos se alternam com grande frequêencia, como é o caso das seqüências aqui estudadas. Essas características conferem ao perfil $R$ respostas marcantes das variações litológicas, muito úteis na identificação de markers para a correlação e reco- nhecimento de sequências granodecrescentes ou granocrescentes, bem como dos tipos de contato entre duas litologias.

O reconhecimento dessas feições são imprescindíveis para a interpretação de registros de ambientes de sedimentação.

O PERFIL DE RAIOS GAMA O perfil de raios gama mede a radiatividade natural das rochas, sendo portanto muito utilizado na deteç̧ão e avaliação de minerais radiativos de potássio e urânio.

Nas rochas sedimentares, o perfil de raios gama geralmente reflete o conteúdo de pelitos porque é neste material que os elementos radiativos tendem a concentrar-se.

\section{OS FORMATOS DAS CURVAS E SEU SIGNIFICADO} NA INTERPRETAÇAO DE AMBIENTES Além dos formatos dos perfis dos raios gama, são importantes suportes na interpretação dos ambientes de sedimentação as informações dos testemunhos de sondagens, e dos afloramentos da área, associando-se todos os dados de natureza textural, estrutural e paleontológico para confronto com as respostas dos perfis geofísicos. Assim, vários padrões de respostas puderam ser identificados e estabelecidos para fácies genéticas especificas.

$O$ contato entre as duas litologias dominantes (arenitos e siltitos) pode-se processar de diversas maneiras (Fig. 3). O contato superior do arenito com pelitos no raio gama pode ser abrupto, transicional ou serrilhado (l). A porção central

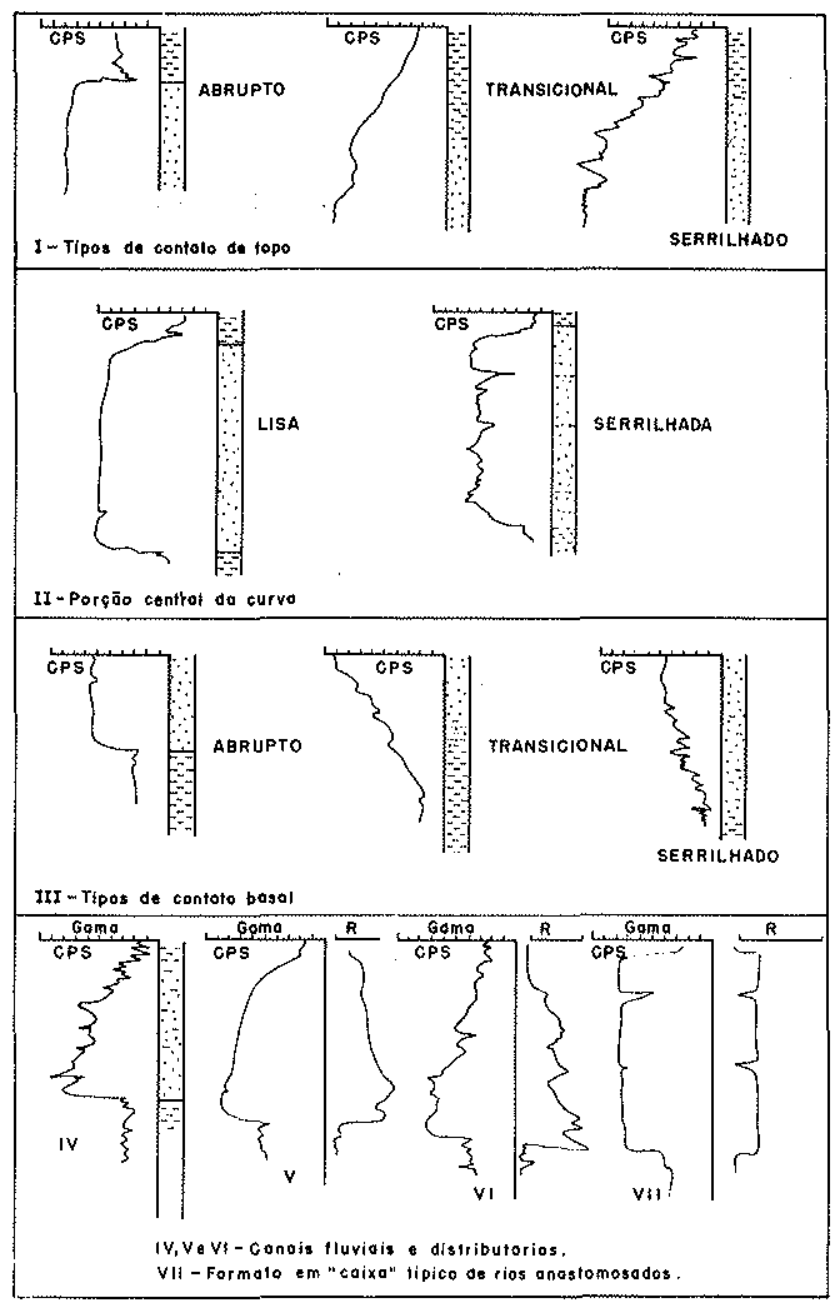

Figura 3 - Respostas dos raios gama e resistividade às variações de litologias e ambientes de sedimentação 
da curva (nos arenitos) pode ser lisa ou serrilhada (II). E, finalmente, o contato basal dos arenitos com os pelitos subjacentes também pode ser abrupto, transicional ou serrilhado (III). A combinação desses padrões e suas repetições em cada ambiente constituem a base de classificação para a interpretação ambiental.

Nos ambientes fluviais, os raios gama respondem para as areias com formatos que têm na base um contato abrupto seguindo por um serrilhado não muito proeminente, terminando por uma deflexão positiva gradual até atingir os siltitos ou folhelhos no topo (IV). A conjunção dos raios gama e de $R$ reproduz em casos de canais fluviais um formato de sino (V) ou árvore de Natal (VI) dependendo de o serrilhado ser mais ou menos proeminente pela presença de níveis de siltitos intercalados nos arenitos.

O contato basal abrupto é uma resposta negativa e resulta da erosão produzida pela alta energia da corrente que transporta areia na base da unidade. Outra resposta típica para ambientes fluviais é refletida por um contato abrupto nas porçð̃es inferior e superior da curva de arenitos, resultando no formado em caixa ou bloco (VII). Geralmente, esses blocos são empilhados, separados uns dos outros por delgadas camadas de sedimentação fina, representadas nas respostas elétricas por deflexões positivas. Essas respostas são obtidas em depósitos de planície de inundação de rios anastomosados (Fig. 4).

QUADRO EXPLICATIVO DA FIGURA OA

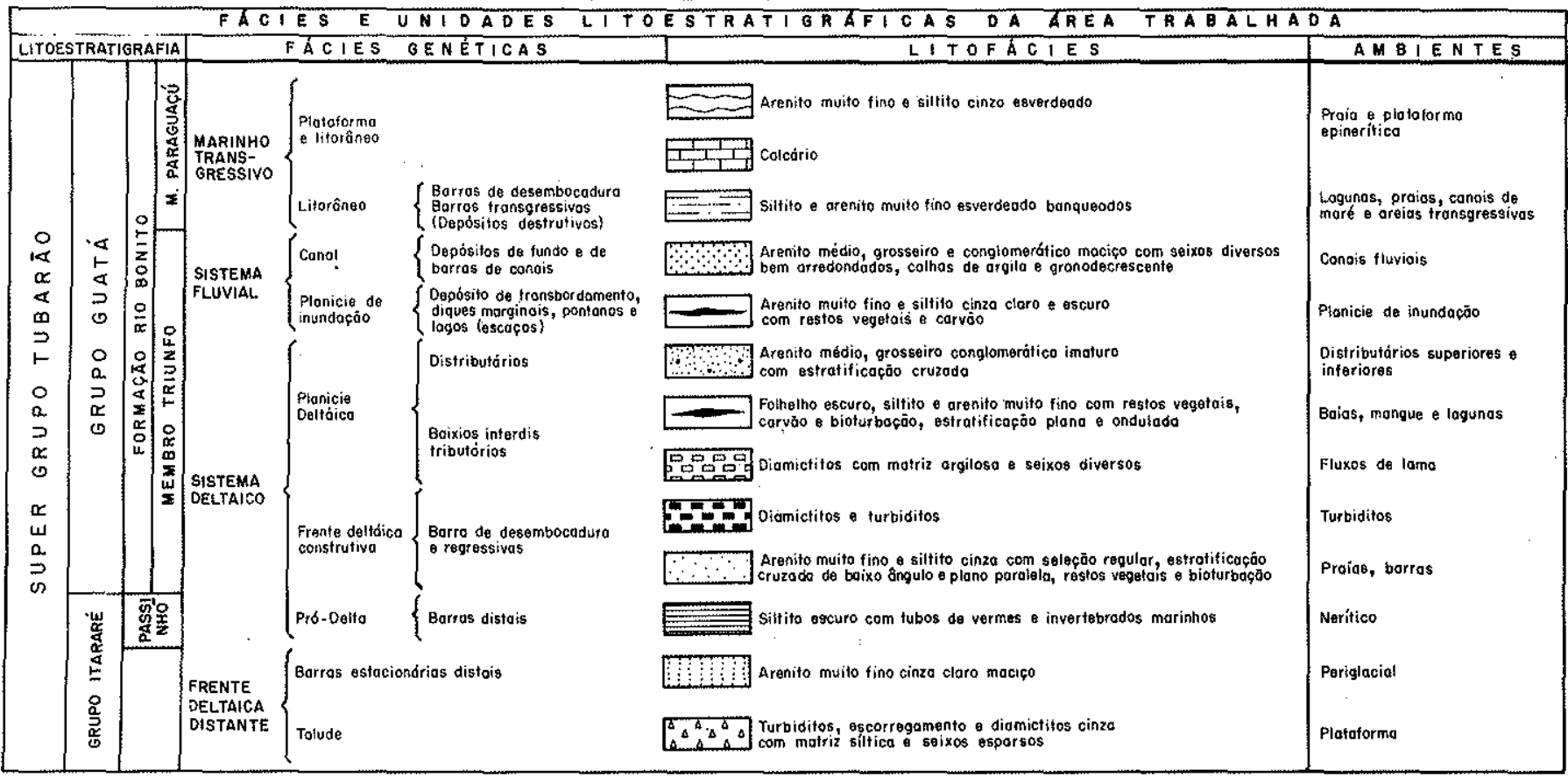

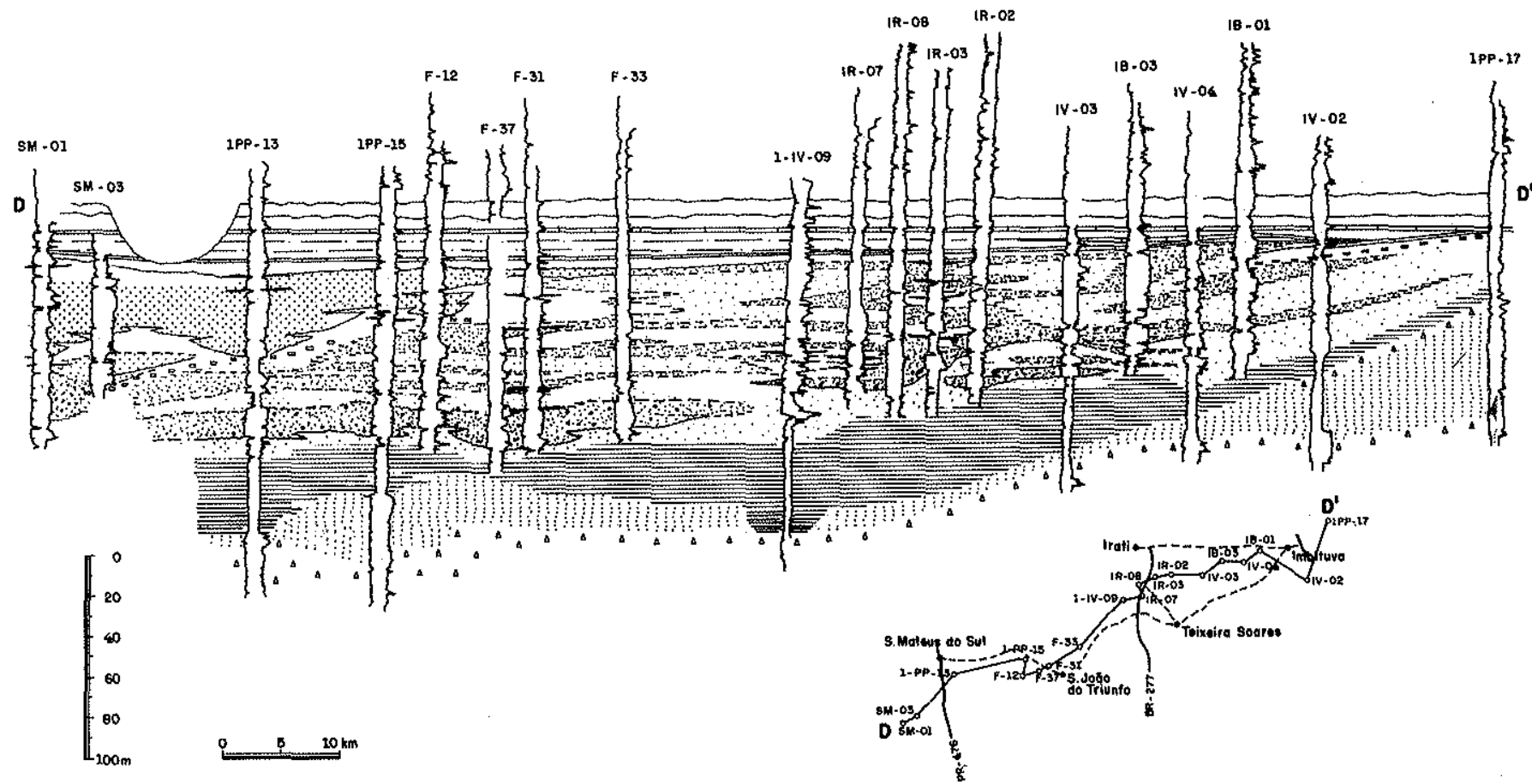

Figura 4 - Fácies e ambientes das unidades estratigráficas trabalhadas em seçao $N-S$ 
O padrão em forma de sino ou árvore de Natal pode também ser encontrado na planície deltaica. Nesses ambientes, a porção média da curva tem respostas variáveis: de lisa, passando por serrilhada, à resposta de desvios positivos bastante proeminentes, dependendo da posição da seção em relação ao distributário. A forma lisa da curva para areias representa alta energia do distributário. O serrilhado é conseqüência das flutuações episódicas da energia no ambiente, transportando tamanhos de grãos de diâmetros variáveis que podem ocorrer em áreas interdistributárias. Na planície deltaica, o contato superior dos formatos de raios gama é normalmente gradacional, terminando por deflexões positivas de sedimentação fina que sugerem a presença de baias, lagunas, diques marginais e pântanos, próprios de ambientes propício à geração de carvão.

A transição altamente serilhada das curvas é bem desenvolvida na frente deltaica e pode representar repetidas oscilações de areias de barras em pelitos marinhos. A curva serrilhada em que os dentes (representados por areias) crescem debaixo para cima (forma de taça), devido ao aumento dos teores de areia, representam barras e barreiras regressivas em seqüências de sedimentação deltaica progradante (frente deltaica sobre o pró-delta) (Fig. 10, poço IV-4).

Formatos serrilhados de aspecto triangular, resultantes de sedimentos arenosos e sílticos com predominância de sedimentação fina no topo, são interpretados como barras e barreiras transgressivas. Nesses formatos, a base não é abrupta, diferenciando-se dos distributários (Fig. 5, poço IV-03).

A possibilidade de aplicar essas informações para outros deltas mostra que as características próprias e persistentes de cada formato podem ser utilizadas com segurança e se obter excelentes resultados, como já fizeram Castro (1980), em ambientes deltaicos do Grupo Itararé e da Formação Rio Bonito em Santa Catarina; Selley (1976), em ambientes do Mar do Norte; Rehbein (1981), na Formação Fort Union; Perrodon (1980); e Cava e Soares (1978).
ANÁLISE E INTERPRETAC̣ÃO FACIOLÓGICA Intervalo D-E (Folhelho Passinho) LITOFÁCIES Constitui-se de siltitos micáceos, por vezes argilosos, piritosos de cor cinza, com interlaminações cinza-escuro e eventuais intercalações de arenitos muito finos.

Apresenta laminação paralela, microestratificação cruzada e laminação ondulada e convoluta. Freqüentemente, mostra-se bioturbado. Contém uma fauna de invertebrados marinhos representados por branquiópodos e peliecípodos.

DISTRIBUIÇÃO E ESPESSURA O intervalo estendese por toda a área com espessura variável, de poucos metros na porção norte (de 2 a $3 \mathrm{~m}$ ) alcançando cerca de $45 \mathrm{~m}$ próximo a Teixeira Soares.

RELAÇÕES DE CONTATO O contato basal, horizonte $E$, é visto apenas nos poços mais profundos (cerca de $14 \mathrm{~m}$ ) e se faz com arenitos muito finos e calcíferos do Grupo Itararé. Ao norte da área, o contato é mantido com uma seqüência de diamictitos que se intercalam entre os arenitos inferiores e os siltitos superiores (Fig. 5).

O topo dos siltitos, horizonte $D$, é gradacional para arenitos muito finos e siltitos. Não obstante a gradação, o contato é muito nítido nas curvas de raios gama e resistividade.

ORIGEM E IDADE Este intervalo foi depositado sob condições marinhas, como indicam seus fósseis. As maiores espessuras do intervalo se distribuem ao redor do corpo arenoso sobrejacente acima descrito, mostrando íntima relação entre os dois pacotes. E, salvo casos específicos, são transicionais por meio de uma seqüência que se acha intercalada entre eles. Dessa forma, os siltitos do Folhelho Passinho constituem o pró-delta; os arenitos sobrejacentes formam a frente deltaica; e o corpo arenoso acima, os canais distributários da planície deltaica.

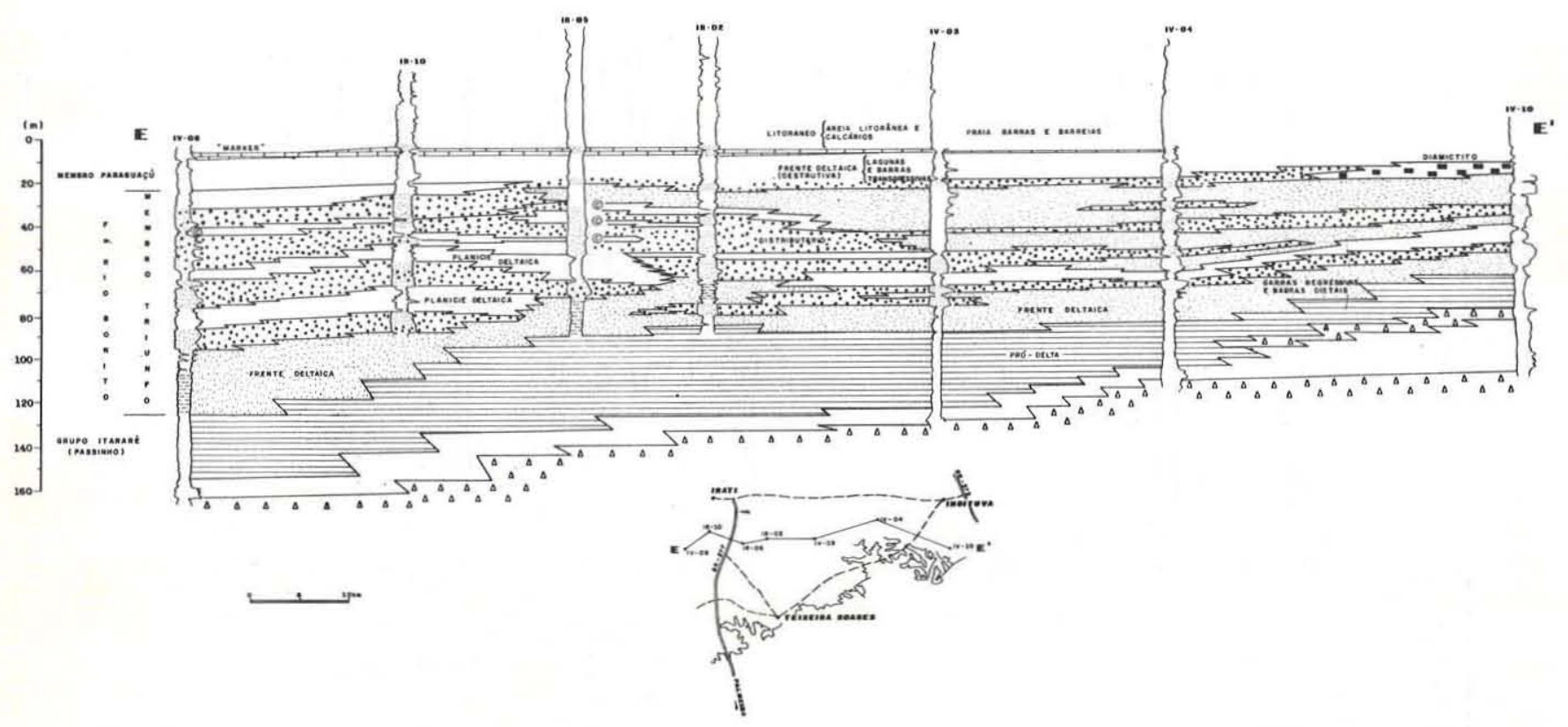

Figura 5 - Seção norte da área, mostrando as relações faciológicas interpretadas a partir dos formatos das curvas de raios gama e resistividade 
Intervalo C-D (porção inferior do Membro Triunfo) · $L I$ TOFACIES DA BASE Este intervalo é constituido, invariavelmente, em sua porção inferior por um siltito arenoso ou um arenito muito fino com lâminas de siltitos micáceos carbonosos, calcíferos, com laminação plano-paralela, microestratificação cruzada, acanalada e ondulada.

Apresenta-se freqüentemente bioturbado e, às vezes, com tubos vermiformes bem preservados.

\section{DISTRIBUIÇAOO E ESPESSURA Distribui-se por qua-} se toda a área, estando ausente em alguns locais. Neste caso, o contato dos siltitos do intervalo $C-D$ se faz diretamente de forma erosiva com os arenitos médios ou grosseiros da litofácies superior. A espessura da litofácies em questão varia de poucos metros a cerca de $18 \mathrm{~m}$.

RELACEAO DE CONTATO O contato inferior, como já foi descrito, é transicional com os siltitos que constituem o Folhelho Passinho; o contato superior, na maioria dos casos, se dá de forma erosiva com os arenitos médios grosseiros ou conglomeráticos da litofácies de canal.

ORIGEM As características litológicas, associadas às estruturas sedimentares, geometria, distribuição e formato das curvas de raios gama e $R$, bem como a posição espacial entre os siltitos marinhos e arenitos de canais de distributários superiores, levam a interpretar essas litologias como depósitos de frente deltaica com perfis elétricos, de barras regressivas típicas, como, por exemplo, nos poços 1B-01 e IV-04, ou barras distais como no F-12 (Fig. 4). Esta mesma litofácies, em muitos casos, pode passar lateralmente para depósitos de baixios interdistributários de planície deltaica.

Litofácies superior São arenitos de granulometria média mal selecionados, amarelados, com intercalações mais grosseiras, apresentando na base níveis conglomeráticos em geral com bom grau de arredondamento. Freqüentemente apresentam granodecrescência, passando para arenitos finos que, por sua vez, podem conter intercalações de siltitos ou siltitos carbonosos no topo.

Siltitos e folhelhos encontram-se geneticamente associados aos arenitos. São de coloração cinza-clara, ou escura, e preto. Enquanto os siltitos são freqüentemente argilosos, micáceos e piritosos, os folhelhos são carbonosos ou contêm leitos de carvão.

Distribuição e espessura $\quad \mathrm{O}$ intervalo $C-D$ distribui-se por toda a área mas com diferentes espessuras. As maiores estão ao sul de Teixeira Soares, alcançando pouco mais de $30 \mathrm{~m}$; diminui em direção ao norte e também na direção SE. Os arenitos de canais e distributários são restritos ao centro da bacia.

Relações de contato O contato entre as três litofácies que compõem o intervalo é na maioria dos casos gradacional. Exceçzes ocorrem tanto no contato basal dos arenitos dos canais distributários menores com os arenitos muito finos e siltitos da frente deltaica, como nos baixios interdistributários onde pode ser abrupto ou mesmo erosivo.

Origem e idade A litofácies basal, descrita no item anterior, constituída de arenitos muito finos e siltitos, representa em sua maior parte depósitos de barras de desembocadura, barras distais e barreiras de frente deltaica.

Os canais basais são progradantes e estão muito bem representados pelos formatos das curvas de raios gama e $R$ dos poços SM-01, IPP-13 e F-31, entre outros. As direções de afluxo predominantes são de leste para oeste e de sul para norte, segundo medições no campo e constatadas pelos mapas de porcentagem de areia (Fig. 6).

Potencial para o carvão As possibilidades de formação de carvão, principalmente no fim deste intervalo, após a construção de boa parte da planície deltaica foram boas, entretanto, fatores diversos inibiram seu desenvolvimento.

O mapa da Fig: 6 mostra que apenas em estritas e limitadas áreas foi possível a formação de carvão (na maior parte lâminas de vitrênio) geralmente associado a folhelhos e siltitos carbonosos.

A limitada ocorrência e a pequena espessura das camadas de carvão podem ser atribuídas em parte ao abandono da planicie deltaica pelos distributários no fim deste intervalo. Essa circunstância paradoxal foi desfavorável, pois inibiu o desenvolvimento da vegetação em áreas propícias em decorrência da invasão do mar sobre a planície subsidente.

A invasão do mar sobre a planície deltaica recém-formada pode ter ocorrido devido:

1. à subsidência da área e/ou ao abandono da planície deltaica pelos distributários com a consequiente diminuição ou parada de suprimentos;

2. ao afundamento de todo o lobo construído em virtude da compactação do Folhelho Passinho (pró-delta) produzida pelo próprio peso das areias da planície deltaica.

Intervalo B-C (porção superior do Membro Triunfo) LITOFACIES Este intervalo caracteriza-se pela predominância de arenitos finos a médios de coloração cinza-esbranquiçada, micáceos, com freqüentes intercalaçóes grosseiras ou conglomeráticas. Os grãos têm uma seleção baixa ou regular e são subangulares a subarredondados.

As estruturas mais comuns são as estratificações cruzadas, acanalada, planar e cruzada. Podem ocorrer galhas de argila.

As espessuras variam entre 5 e $15 \mathrm{~m}$. Entre os corpos arenosos colocam-se siltitos ou arenitos muito finos, carbonosos com camadas geralmente de 1 a $6 \mathrm{~m}$, possuem estratificação ondulada, microcruzada, flaser acanalada. Podem apresentar bioturbação.

A essas litologias estão comumente associadas lâminas de vitrênio ou finos leitos de carvão.

Ocorrem ainda diamictitos intercalados às litologias acima descritas. Estes são de coloração cinza-escuro, passando a cinza-claro esverdeado ou avermelhado. Os seixos são esparsos e medem, em sua maioria, cerca de $1 \mathrm{~cm}$ de diâmetro, podendo alcançar até $8 \mathrm{~cm}$. São em geral arredondados e podem ser formados por diferentes litologias (quartzitos, gnaisses e mesmo sedimentos).

DISTRIBUIÇÃO E ESPESSURA OS arenitos distribuem-se sob a forma de pacotes geralmente contínuos, seguindo determinadas direções com espessuras entre 5 e $15 \mathrm{~m}$.

Os siltitos constituem intercalações que se repetem verticalmente no intervalo de 3 a 9 vezes, sendo mais comum 5 vezes.

Dessas intercalações, freqüentemente, uma é portadora de niveis de vitrênio ou leitos de carvão; raramente duas como nos poços 1PP-13, F-31 (Fig. 4) e esporadicamente três como no poço IR-05 (Fig. 5).

Os diamictitos-encontram-se distribuídos em torno de São Mateus do Sul, num raio de aproximadamente $20 \mathrm{~km}$, estendendo-se até Mallet, conforme consta no poço M-1APR perfurado pela Petrobrás. Ao norte de Imbituva, cobrem uma área ovalada cujo diâmetro máximo atinge aproxima- 

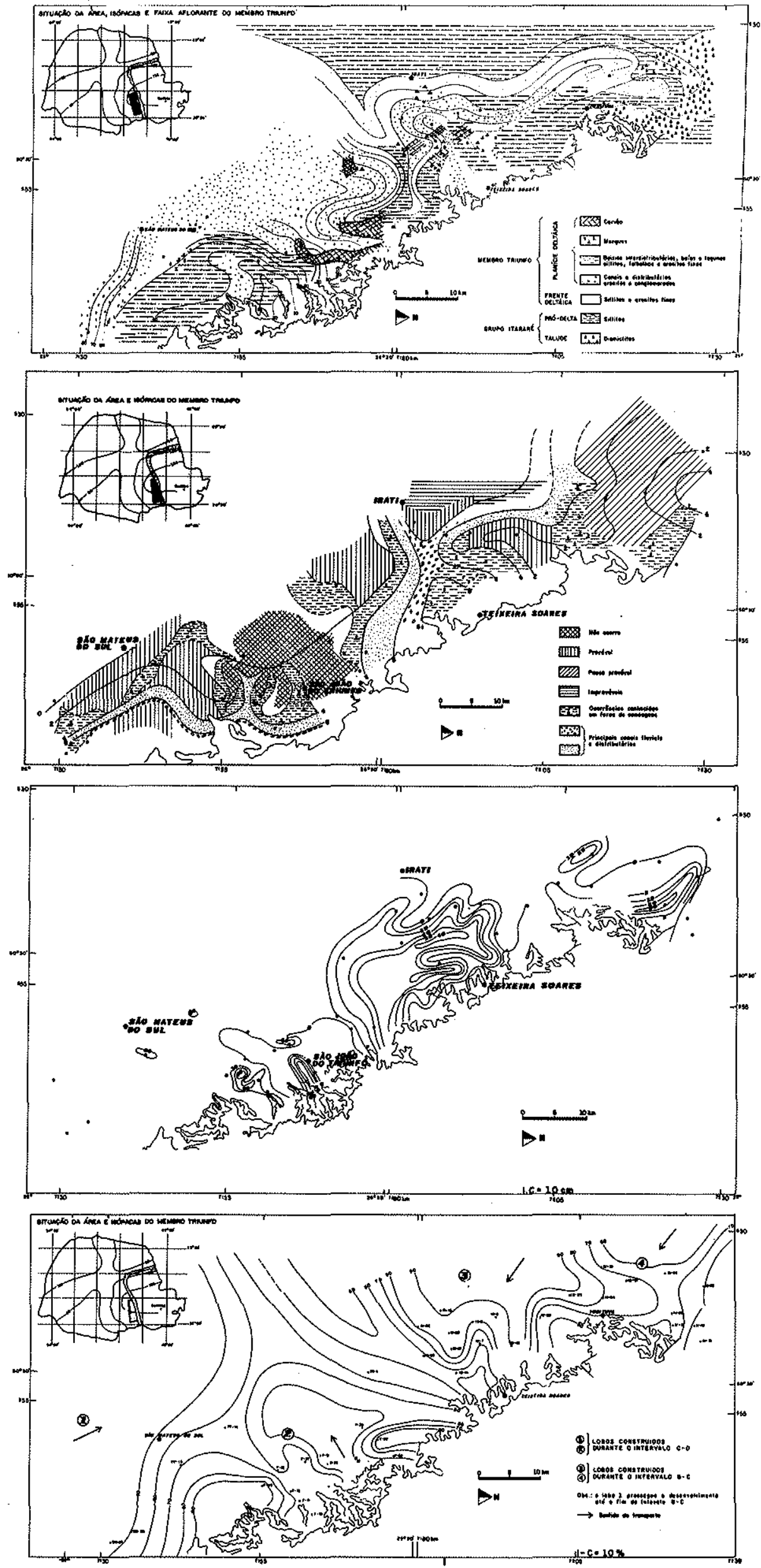

Figura 6 - Membro Triunfo Inferior (in (ervalo c-d). Mapa combinado de fácies $e$ porcentagem de areia indicando os locais de ocorrências de carvão

Figura 7 - Porçđo superior do Membro Triunfo. Mapa de distribuição das camadas de carváo e novas areas favoráveis combinado com o mapa de dispersão das areias (intervalo b-c)

Figura 8 - Porçao superior do Membro Triunfo (intervalo b-c). Mapa isolitico dos carvões

Figura 9-Porcentagem de areia 
damente $20 \mathrm{~km}$. No sul, a espessura alcança $10 \mathrm{~m}$ no centro do corpo, constatado no poço Petrobrás RC-1-PR, adelgaçando-se em direção aos bordos até desaparecer. Ao norte, na região de Imbituva, a espessura máxima atinge $9 \mathrm{~m}$, adelgaçando-se também para os bordos até desaparecer. Enquanto no sul da área os diamictitos encontram-se na porção média do intervalo, no norte da área ocupam o topo, servindo de limites para o intervalo seguinte $\left(A_{1}-B\right)$, que vem a constituir a parte basal do Membro Paraguaçu (Figs. 5 e 6).

RELAÇÕES DE CONTATO Os arenitos, salvo casos específicos, são erosivos sobre os siltitos. Os perfís elétricos têm a forma de caixotes com a porção basal abrupta. $O$ topo do caixote pode ter urna superfície um pouco menor que a base, resultando da granodecrescência dos corpos arenosos que terminam com siltitos.

Os diamictitos relacionam-se com os arenitos ou siltitos sempre por um contato brusco tanto na base como no topo, pois são produtos de eventos distintos. Os arenitos, muito finos na porção superior do intervalo, têm relações concordantes com as litologias inferiores.

ORIGEM Os arenitos finos, médios e conglomeráticos, que constituem a maior parte do intervalo, são provenientes de canais e distributários que compõem os lobos deltaicos.

Durante a construção dos lobos mencionados neste intervalo, foram por diversas vezes criadas condições para a formação de leitos de carvão, de preferência nos baixios interdistributários. Essa configuração é muito clara no mapa da Fig. 8, que reúne todos os leitos de carvão deste intervalo, quando comparado com o mapa da Fig. 7.

Litofácies de difícil interpretação genética é aquele representado pelos diamictitos.

Não é seguro que os diamictitos identificados nos poços possam realmente ser traçados lateralmente como corpos contínuos. Mesmo assim eles parecem representar um evento importante, dada a extensão da área que ocupam numa certa fase da sedimentação do Membro Triunfo.

POTENCIAL PARA CARVÃO Os leitos de carvão acumularam-se sobre os lobos deltaicos, de preferência nos baixios interdistributários, não distante dos principais distributários, e, eventualmente, em pequenas lagunas e antigos mangues protegidos por barras.

A preferência pelos lobos deltaicos verifica-se quando se comparam os mapas de distribuição das ocorrências de carvão (Fìg. 7) e de isólitas de carvão do intervalo $B$ - $C$ (Fig. 8).

O mapa de isólitas de camadas de carvão (Fig. 8) mostra que as espessuras diminuem em direção as extremidades dos lobos e, consequientemente, para o centro da bacia. Se essa tendência for confirmada, as expectativas de ocorrências de maiores espessuras naquela direção ficarão consideravelmente reduzidas. Este mapa foi construído com base nas ocorrências de camadas de carvão nos poços existentes na área e não significa que haja necessariamente continuidade entre os leitos em toda sua extensão, dada a exigüidade de poços, mas reflete as áreas de maior número de ocorrências, maior soma das espessuras e os limites prováveis das ocorrências. Os carvőes deste intervalo têm uma espessura entre 10 e $50 \mathrm{~cm}$ e é pouco provável que ocorram camadas com espessuras mais significativas, pois as condiçðes requeridas para a acumulação e a preservação da matéria orgânica em quantidades suficientes para desenvolver camadas mais espessas de carvão nesta área não puderam ser reconhecidas.
Rösler (1970) descreve a ocorrência de uma flora de Paracalamites, Annularia, A. accidentalis, Equisetales e Astherotheca.

Chama a atenção para a existência de restos de vegetais encontrados que, por suas características, não sofreram transporte. Foram encontrados, também, vegetais que sofreram transporte, como Glossopteris. Essas ocorrências foram registradas em São João do Triunfo e Teixeira Soares.

Sommer et al. (1981), estudando o conteúdo paleobotânico de Marins, localidade situada entre Reserva e Ipiranga, cerca de $50 \mathrm{~km}$ ao norte de Imbituva, encontraram as mesmas formas típicas que ocorrem na área trabalhada por Rösler (op. cit.).

Os resultados dos trabalhos acima mencionados mostram sobretudo que havia condições paleoclimáticas favoráveis ao desenvolvimento de uma vegetação e que esta se desenvolvéu com bastante intensidade. Se vegetação havia nessas áreas, certamente faltaram outras condiçðes para a formação de carvão, como se verá adiante.

Segundo Wanless et al. (1969), os padrões ambientais ou as condições paleogeográficas ideais para a acumulação do carvão devem enquadrar-se em alguma das seguintes:

1. uma planície exposta após uma brusca regressão marinha;

2. deposição numa costa estreita e despojada, semelhante a algumas costas pantanosas do Atlântico atual;

3. distribuição de sedimentos controlada pelo desenvolvimento de extenso delta;

4. acumulação de carvão em estuário e posterior afogamento deste.

Stach et al. (1975) relacionam as condiçoes paleogeográficas e também tectônicas requeridas como pré-requisito para o desenvolvimento de espessas camadas de turfa e, conseqüentemente, para a formação de carvão. São elas:

1. uma lenta e contínua elevação do nível do lençol freático mantendo continuadamente condições para a formação da turfa; isto é, subsidência;

2. proteção de mangues por praias, barras de areia, cordoes etc., contra inundaçōes pelo mar e presença de diques naturais contra violentas inundaçôes de águas fluviais;

3. relevo de baixa energia para o interior e também um suprimento de sedimentos fluviais com limitaçðes, caso contrário haverá interrupção da formação da turfa.

Caso a subsidência seja muito rápida, os' pântanos poderăo ser afogados (haverá elevação do nível d'água) e, então, se processará uma sedimentação sob condições límnicas ou marinhas (argilas, margas ou calcários) em detrimento.da matéria vegetal.

Caso a subsidência seja muito lenta, os materiais provenientes dos vegetais ficarão na superfície, decompor-se-ão em condiçð̌es aeróbias, e, se alguma turfa se formar, será erodida.

A formação do carvão, como se vê, depende de uma estreita relação entre as condições paleogeográficas e tectônicas dentro de uma área de sedimentação. Outro fator complementar que influi na formação do carvão é o clima.

Voltando a considerar a área em questão, ao sul do Arco de Ponta Grossa, podemos agora relacionar, lado a lado, os fatores positivos e negativos que poderiam ter ocorrido na área, influenciando qualitativa e quantitativamente a formação e preservação do carvão.

\section{Fatores positivos}

1. Construção de um delta progradacional.

2. Subsidência da área. 
3. Condiçōes climáticas satisfatórias (provavelmente as mesmas do Estado de Santa Catarina, onde se formou o carvão) e presença de vegetais, como revelam os estudos paleobotânicos.

\section{Fatores negativos}

1. Suprimento de sedimentação em taxas elevadas em certas épocas maior que a subsidência.

2. Movimentos epirogenéticos positivos e negativos, talvez sob influência dos arcos de Ponta Grossa e Porto União, ou o alinhamento Guapiara colocando, por vezes, a matéria orgânica em condições oxidantes e, por outras, ocasionando invasão por marés sobre a planície deltaica, limitando o desenvolvimento da turfa.

3. Ambiente de sedimentação de alta energia com predomínio de areias, proporcionando o transporte da matéria orgânica além da planície deltaica.

4. Oxidação e erosão da turfa acumulada por abandono e reocupação da planície deltaica.

Os fatores positivos foram evidenciados pela documentação gráfica e interpretação dada no decorrer deste trabalho.

Em relação aos fatós negativos, uma análise pode ser feita para justificar essas colocações.

O mapa de porcentagens de areia para todo o Membro Triunfo (Fig. 9) mostra que as porcentagens de areia extraidas dos perfis dos poços ficam entre $70 \%$ e $90 \%$. Um mapa de razão areia/folhelho construido para o intervalo $B-C$ mostra que o valor 2 , ou seja, um máximo de $35 \%$ de pelitos, ocupa apenas pequenas porções isoladas da área, portanto um ambiente de excessiva energia para o desenvolvimento de turfeiras.

O item 2 refere-se a movimentos epirogenéticos, que poderiam ter ocorrido na área e podem ser relacionados com os Arcos de Ponta Grossa e Porto União, e alinhamento de Guapiara. Tudo isso é mencionado em diversos trabalhos, tais como Medeiros et al. (1971), Northfleeth (1969) e Thomaz Filho (informação pessoal).

Por outro lado, por ocasião de rápida subsidência, ou afundamento, parte da planície deltaica pode ter sido invadida por águas marinhas nocivas ao desenvolvimento vegetal enquanto em outras pode ocasionar um excessivo aumento do nivel freático afogando a vegetação e sustando seu desenvolvimento. Neste caso, a vegetação passa a decompor-se em condiçoes anaeróbias sob um corpo de água com uma espessura excessiva para a renovação da vegetação.

Correa da Silva (1981) estudou amostras de carvão da área de Irati apresentou a seguinte interpretação para a gênese dessas rochas: as amostras analisadas correspondem à Fácies Sapropélicas depositadas em ambiente subaquático, redutor", onde se desenvolve intensa atividade bacteriana, degradando a matéria orgânica presente, conforme atestam os altos teores de pirita, as resinas amorfas, as vitrinitas intensamente impregnadas e a presença de algenita.

Ainda, segundo o relatório, tanto a análise palinológica como a petrográfica indicam a existência de tecido lenhoso, ligno celulósico (vitrinita e fusinita) e de abundantes elementos de composição à base de lipídios como esporos, algas, cutículas e resinas. Tais elementos depositaram-se em ambientes subaquosos, mais ou menos profundos, de águas calmas, mas, neste caso, a intensa degradação dos lipidios e a presença de frambóides de pirita evidenciam uma gênese em condições anaeróbias, intensamente redutoras, mais prọprias de ambientes geradores de óleo ou folhelho oleigeno que de turfeiras formadoras dos carvões húmicos.
Intervalo $\mathrm{A}_{1}-\mathrm{B}$ (parte inferior do Membro Paraguaçu) LITOFACIES Este intervalo é constituído predominantemente por siltitos, cinza-claros e esverdeados, arenitos de granulação muito fina ou média e leitos de calcários. Como estruturas encontram-se laminaçðes onduladas, flaser e bioturbações.

Esses siltitos podem constituir corpos contínuos, atingindo até $15 \mathrm{~m}$ de espessura.

Os leitos de calcários são peculiares neste intervalo. Cada leito tem em média $60 \mathrm{~cm}$ de espessura.

DISTRIBUIÇÃO E ESPESSURA Este intervalo distribui-se por toda a área com uma espessura média de $18 \mathrm{~m}$, adelgaçando-se para o norte, onde se reduz a 2 e $4 \mathrm{~m}$.

RELAÇÕES DE CONTATO O limite superior do intervalo é definido pela camada de calcário utilizada como marco de referência para toda a seção.

O limite inferior do intervalo, e que vem a ser o contato entre os membros Triunfo e Paraguaçu, é freqüentemente muito nítido e persistente, mas em determinados locais grada de forma que os limites devem ser arbitrados.

Ao norte da área, o contato entre os dois membros pode ser arbitrado imediatamente acima dos diamictitos, como já sugeriram Nagalli et al. (1981).

ORIGEM Os sedimentos pertencentes a este intervalo são, em sua porção basal, o resultado do retrabalhamento dos depósitos da planície deltaica, logo após o início da transgressão do Mar Paraguaçu.

Algumas finas lâminas de carvão encontradas na base do intervalo, como no furo IR-05, e galhas de carvão, no furo SM-01, têm sua gênese relacionada com um sistema de lagunas e mangues costeiros logo em seguida afogados pela transgressão impedindo a formação do carvão.

Intervalo $\mathrm{A}-\mathrm{A}_{\mathrm{l}}$ (Parte média do Membro Paraguacu) Este intervalo encontra-se em grande parte erodido na área. Os estudos realizados neste intervalo objetivaram apenas melhorar a correlação entre os poços e auxiliar na interpretação ambiental.

Nesta época, a área encontrava-se sob condiçôes dominantemente marinhas e caracterizava-se por depósitos de plataforma e litorâneos, com registros de barras e praias, notadamente na região nordeste da área, próximo a Imbituva.

EVOLUÇÃo PALEOGEOGRÁFICA A deposição dos sedimentos da Formação Rio Bonito na área resultou, em grande escala, na construção de dois lobos deltaicos integrantes de um sistema deltaico maior, que se estende para o sul até a região de Orleãs, Santa Catarina, já definido anteriormente por Medeiros e Thomaz Filho (1973) e Castro (1980). Os depósitos são típicos de um delta altamente construtivo que se desenvolveu de um corpo de água salgada que denominamos Mar Passinho na época Artinskiano-Kunguriano (Daemon e Quadros, 1969).

A porção continental, na época, deveria constituirr-se por uma paisagem que ainda preservava as características impressas pela ação glacial, criando condições para o desenvolvimento de sistemas fluviais anastomosados com drenagem de direção geral E-W para o Mar Passinho.

Este sistema fluvial desenvolvido originou um delta progradante, de modo que hoje se encontra preservada vertical e lateralmente a seguinte seqüência: pró-delta (Folhelho Passinho); frente deltaica (parte inferior da Formação Rio Boni- 
to); planície deltaica (distributários e baixios interdistributários); e, finalmente, sistema fluvial anastomosado recobrindo a seqüência (parte superior do Membro Triunfo). Todo esse registro acha-se bem preservado na porção sul da área, conforme a Fig. 4.

Os depósitos do sistema fluvial avançaram progressivamente sobre a planície deltaica e são caracterizados por suas unidades arenosas. Sedimentos argilosos e sílticos provenientes de depósitos de transbordamento são muito pouco expressivos.

A descarga desses sedimentos no Mar Passinho resultou na construção de lobos deltaicos justapostos formados por uma extensa planície deltaica recortada por distributários; nos baixios interdistributários desenvolveram-se turfeiras, originando as atuais finas camadas de carvão. Subjacente e lateralmente aos sedimentos da planície deltaica, encontramse bem caracterizados depósitos de barras regressivas que constituíram parte da frente deltaica.

Após a formação da planície deltaica do intervalo $C-D$, a área abrangida aproximadamente pelo lobo central foi lentamente abandonada pelos distributários e passou a ter maior influência marinha e em parte subaérea.

Após essa fase surgem novos lobos e baías (intervalo $B-C)$. No final do intervalo $A_{1}-B$, já próximo do topo do Membro Triunfo, teve início ao norte de Imbituva o desenvolvimento de norte para sul de um último pequeno lobo, que prosseguiu até o início da transgressão do Mar Paragua$c u$. Este tem, em seu limite nordeste, depósitos de diamictitos interpretados como de escorregamento subaquoso.

Sobre a superfície dos últimos lobos construídos, até a base do Membro Paraguaçu, por diversas vezes formaram-se turfeiras efêmeras originando as finas camadas de carvão.

No fim do Kunguriano, finalmente, uma transgressão marinha penetra sobre o continente, inicialmente por meio de baías e baixios interdistributários, passando a recobrir a planície deltaica e retrabalhar os sedimentos até então depositados.

Com a transgressão, foram intensificados os processos de ação das ondas e correntes ao longo da costa, e de marés sobre a planície deltaica. Os depósitos de mangues foram erodidos e redepositados, incluindo as turfas, caso se tenham formado.

Os corpos de areias passaram a formar depósitos de barreiras transgressivas. Como resultado final, toda a planície deltaica foi invadida pela transgressão e principalmente a areia derivada foi transportada e redistribuída sobre a costa.

Essa transgressão atingiu sụa plenitude no Kazaniano com a deposição de sedimentos sublitorâneos da Formação Palermo.

\section{CONCLUSÕES A respeito da porção basal da For- mação Rio Bonito e suas relações com o Grupo itararé (Folhelho Passinho) Os sedimentos basais da Formação Rio Bonito são arenitos muito finos de frente deltaica, que se apresentam diretamente sobre folhelhos e siltitos, constituin- tes do Folhelho Passinho, de origem marinha, e que vem a ser o pró-delta do sistema deltaico do Membro Triunfo ao qual está, por conseguinte, geneticamente ligado.}

Sobre as fácies e ambientes deposicionais do Membro Triunfo A porção inferior do Membro (intervalo $C-D$ ), situada imediatamente acima do Folhelho Passinho, constituída de arenito muito fino é, em sua maior parte, depósito de barras e barreiras de frente deltaica relacionadas ao início da progradação.
Lateralmente, e avançando sobre esses depósitos, desenvolvia-se a planície deltaica progradante, onde nos baixios interdistributários se formaram finos leitos de carvão.

A porção média e superior do Membro Triunfo, intervalo $B-C$, resulta da continuidade da construção do delta de forma retrogradacional, desenvolvendo pequenos lobos em áreas distintas, separadas por baías abertas e lagunas. Sobre os lobos de constituição predominantemente arenosa, por diversas vezes criaram-se condições para a formação de carvão.

Os distributários apresentavam características de canais anastomosados, com alta energia, indicadora de um sistema deltaico tipo cuspidado ou leque deltaico, destrutivo com transporte de NW para SE.

O topo do intervalo $B-C$ é interrompido por depósitos marinhos transgressivos do Membro Paraguaçu.

Sobre a gênese e características dos carvớes da área 1. Os carvðes do intervalo inferior $(C-D)$. encontram-se sobre a planície deltaica construída durante a progradação e tiveram sua gênese relacionada à vegetação desenvolvida junto aos diques marginais, pântanos e canais abandonados.

As espessuras não ultrapassam a algumas poucas dezenas de centímetros e encontram-se associadas a leitos de siltitos, arenitos finos e folhelhos depositados imediatamente acima de camadas de arenitos formados por canais distributários.

Os fatores genéticos anteriormente discutidos, e responsáveis pela pequena espessura e distribuição desses carvões, e os resultados das análises petrográficas e químicas desestimulam pesquisas mais detalhadas neste intervalo. Dessa forma, a porção inferior do Membro Triunfo, corres. pondente ao intervalo $C$ - $D$ (entre 15 e $20 \mathrm{~m}$ de espessura), pode ser abandonado em eventuais perfuraçðes na área.

2. Os leitos de carvão no intervalo $B-C$ acumularam-se também sobre os lobos deltaicos, de preferência nos baixios interdistributários, não distantes dos principais distributários e no final do intervalo em lagunas e mangues protegidos por barras.

Os carvões têm uma espessura entre 10 e $50 \mathrm{~cm}$ e pequena distribuição lateral, passando frequientemente a folhelhos carbonosos e siltitos.

Os estudos realizados por Correa da Silva (1981) revelam um carvão de baixo rank e fácies mistas húmica-sapropélica, tratando-se portanto de uma rocha potencialmente produtora de óleo e gás.

3. A área situada entre São João do Triunfo, Irati e Tejxeira Soares, vista à luz da interpretação dos ambientes, foi a mais favorável à geração de carvão, o que se pode assegurar pela qualidade e pela espessura das camadas.

4. A área situada a $10 \mathrm{~km}$ ao sul de Teixeira Soares (Mineiros Primeiros) pode apresentar algum potencial, não estando ainda devidamente avaliada.

5. A distribuição das fácies genéticas mostra que os ambientes favoráveis à geração de carvão têm suas ocorrências e extensões reduzidas da faixa de afloramento para o interior da bacia, onde passam a dominar inteiramente os processos marinhos destrutivos.

Os estudos demonstram também que há uma tendência para um menor número de camadas, culminando com seu desaparecimento em direção ao centro da bacia.

Agradecimentos Este trabalho é um resumo da Tese de Doutoramento apresentada no Curso de Pós-Graduação em Geociências da Universidade Federal do Rio Grande do Sul. Por isso, queremos deixar aqui consignados nossos agradecimentos à Professora Yvonne T. Sanguinetti, Coordenadora 
do Curso e à Professora Zuleika C. Corrêa da Silva, Orientadora; e também aos membros da Comissão Julgadora: doutores Antônio Thomaz Filho, Jorge A. Villwock, Luiz R. S. Martins e Riad Salamuni, pelo apoio e pelas sugestões apresentadas. Nossos agradecimentos estendem-se ainda ao Dr. Paulo César Soares, idealizador e orientador deste tra- balho; ao Geólogo Elimar Trein, Diretor Técnico da Mineropar, da qual recebemos apoio de campo e escritório; bem como aos demais colegas que de alguma forma colaboraram. Para este trabalho, contamos com o suporte financeiro das seguintes entidades: Universidade Federal do Paraná, Capes e Mineropar.

\section{BIBLIOGRAFIA}

AMERICAN ASSOCIATION OF PETROLEUM GEOLOGISTS - 1976 Ancient, Deltas. Tulsa, Oklahoma. AAPG reprint series n? $19.226 \mathrm{pp}$.

CASTRO, J.C. - 1980 - Fácies, ambientes e sequências deposicionais das For. maçoes Rio do Sul e Rio Bonito, Leste de Santa Catarina. Rel. Petrobrás/Cenpes.

CORREA DA SILVA, Z.C. -- 1981 - Interpretação das análises petrográficas e químicas das rochas do Projeto lrati, PR. Rel, int. Nuclebrás/Mineropar.

DAEMON, R.F. e QUADROS, L.P. - 1969 - Bioestratigrafia e palinologia do Paleozóico da Bacia do Paraná. Relatório Interno Petrobrás/Desul/Setex no. 384.

DAPPLES, E.C. e HOPKINS, M.E. - 1969 - Environments of coal deposition. Boulder, Co., Geological Society of America. $204 \mathrm{pp}$.

FISHER, W.L. - 1969 - Facies characterization of Gulf Coast basin delta systems, with some Holocene analogues. Gulf Coast Geological Societies. Transactions, Shreveport, Louisiana 19:239-261.

FISHER, W.L. et al. - 1970 - Depositional systems in the Jackson Group of Texas; their relationship to oil, gas, and uranium, Gulf Cost Association of Geological Societies. Transactions, Shreveport, Louisiana 20:234-261.

LANGE, F.W. - 1944 - Novas localidades fossillferas da Série Itararé no Estado do Paraná. An da Acad. bras. Cienc. 16(4):279-280.

MEDEIROS, R.A. e THOMAZ FILHO, A. - 1973 - Fácies e ambientes deposicionais da Formação Rio Bonito. Anais XXVII Congr. Bras. Geol. Aracaju 1973, SBG. 3:3*12.

NAGALLI, J.T. et al. - 1981 - Projeto Irati; Mapeamento faciológico. Curitiba, Mineropar-SG-MNE. 4v. Mapas escalas 1:10000.

NORTHFLEET, A.A., MEDEIROS, R.A. e MUHL.MANN, H., - 1969 Reavaliação dos dados geológicos da Bacia do Paraná. Rel. Int. da Petrobrás/Desul, n. 385.

PERRODON, A. - 1980 - Geodinamique Petrolifère. Masson ed., Elf Aquitaine, pp. 108-115.

POPP, M.T.B. - 1981 - Branquiópodas e pelecípodas do subgrupo Itararé, Bacia do Paraná, PR (Inédito).
REHABEIN, E.A. - 1978 - Depositional environments and lignite resources of the Fort Union Formation, West-Central North Dakota. Wiliston Basin Symposioum, Montana Geological Society, pp. 295-305.

ROSLER, O. - 1979 - Plantas fósseis de São João do Triunfo (PR); Formação Rio Bonito e suas implicaçðes geológicas. Atas $2^{\circ}$ Simp. Reg. Geol, SBG (SP) 1:181-194, Rio Claro.

SCHNEIDER, R.L. et al. - 1974 - Revisão Estratigráfica da Bacia do Paraná. Anais XXVIII Congr. Bras. Geol., Porto Alegre 1974, SBG. $1: 41-66$.

SELLEY, R. - 1978 - Ancient Sedimentary Environments and thein subsurface diagnosis. Ithaca, New York, Cornell Univ. Press, $287 \mathrm{pp.}$

SELLEY, R. - 1976 - Subsurface environmental analysis of North Sea Sediments. Bulletin of American Association of Petroleum Geologists 60(2): 184-195.

SOARES, P.C. e LANDIM, P.N.B. - 1977 - Contribuição ao estudo do delta do Rio Doce: Aspectos geomorfológicos. Notícias Geomorfológi cas 17(34):47.58.

SOARES, P.L. e CAVA, L.T. - 1982-Faciologia e Potencial carbonifera da Formação Rio Bonito no norte do Estado do Paraná. Anais XXXII Congr. Bras. Geol, Salvador 1982, SBG. 3:1120-1128.

SOMMER, M.G. et al. - 1981 -. Contribuição ao estudo da tafoflora da Formação Rio Bonito (Membro Triunfo) na área de Marins, Estado do Paraná. Atas 3. Simp. Reg. Geol., Curitiba 1981, SBG (SP) 2:190-194.

STACH, E. et al. - 1975 - Coal petrology, 2a ed., Berlim, G. Borntrraeger, $428 \mathrm{pp}$.

WANLESS, H.R., BAROFFIO, J.R. e TRESCOTT, P.C. $-1969-$ Condition of deposition of Pennsylvania coal beds. In: Daplles, $\mathrm{C}$ e Hophins, M.E. (eds.), Environments of coal deposition. Boulder, Colo., American Association of Petroleum Geologists. pp. 114, 105-142.

MANUSCRITO

Recebido em 31 de marco de 1983 Revisão aceita em 07 de abril de 1983 